\title{
Hyperinsulinemia as a Risk Factor for Restenosis After Coronary Balloon Angioplasty
}

\author{
Michinori Imazu, MD; Kotaro Sumii, MD; Hideya Yamamoto, MD; \\ Mamoru Toyofuku, MD; Tomokazu Okimoto, MD; Yukihiko Gomyo, MD*; \\ Hironori Ueda, MD**; Yasuhiko Hayashi, MD**; Nobuoki Kohno, MD
}

\begin{abstract}
The present study evaluated whether hyperinsulinemia is a predictor of restenosis after coronary balloon angioplasty in 69 patients who underwent elective coronary balloon angioplasty; patients were excluded if they were known diabetics being treated with insulin. Quantitative coronary angiography was performed before and after angioplasty and at follow-up. Restenosis was defined as the presence of $\geq 50 \%$ stenosis at follow-up. Plasma insulin responses before, 30, 60, and $120 \mathrm{~min}$ after $75 \mathrm{~g}$ glucose load (OGTT) were measured. Plasma insulin levels were higher in patients with restenosis than in patients without restenosis. Minimal lumen diameter at follow-up was smaller, and percent diameter stenosis at follow-up was higher and late loss was greater in the highest sum of insulin levels during OGTT ( $\Sigma$ insulin) quartile $(0.95 \pm 0.15$ vs $1.47 \pm 0.09 \mathrm{~mm}, \mathrm{p}=0.005 ; 66.3 \pm 5.8$ vs $40.5 \pm 3.3 \%$, $\mathrm{p}=0.0003 ; 0.90 \pm 0.15$ vs $0.49 \pm 0.08 \mathrm{~mm}, \mathrm{p}=0.02$ ). Even after adjustment for coronary risk factors and administration of angiotensin converting enzyme inhibitors, the association of hyperinsulinemia with restenosis leads to the conclusion that hyperinsulinemia is a strong risk factor for restenosis. (Jpn Circ J 2001; 65: $947-952)$
\end{abstract}

Key Words: Coronary heart disease; Hyperinsulinemia; Restenosis

$\Delta$ lthough the introduction of new devices for angioplasty and improvements in the balloon technique have reduced complications during the procedure, restenosis after percutaneous coronary angioplasty (PTCA) remains a serious problem. Neointimal hyperplasia caused by smooth muscle cell (SMC) proliferation and migration, regulated by various growth factors, has been suggested as the main mechanism of restenosis!

Some studies 2,3 have shown that insulin stimulates the proliferation of arterial SMC and increases vascular cell mitogenesis and protein synthesis, particularly matrix proteins such as type IV collagen. Aortic SMC proliferation after endothelial injury was promoted in the obese Zucker rat model, which is characterized by early spontaneous development of hyperinsulinemia and insulin resistance? Moreover, insulin sensitizing agents, the thiazolidinediones, inhibit SMCs proliferation and migration in a rat balloon injury model 6

However, an association with hyperinsulinemia and restenosis after PTCA is controversial and only a few studies 7,8 have shown a positive association. Rabbani et al showed a negative association between hyperinsulinemia and restenosis after excimer laser angioplasty? The aim of the present study was to evaluate whether hyperinsulinemia is a predictor of restenosis after PTCA.

(Received May 10, 2001; revised manuscript received August 3, 2001; accepted August 6, 2001)

Second Department of Internal Medicine, Hiroshima University School of Medicine, *Department of Cardiology, Mazda Hospital and **Department of Cardiology, Tsuchiya General Hospital, Hiroshima, Japan

Mailing address: Michinori Imazu, MD, Second Department of Internal Medicine, Hiroshima University School of Medicine, 1-2-3 Kasumi, Minami-ku, Hiroshima 734-8551, Japan. E-mail: imazu@ hiroshima-u.ac.jp

\section{Methods}

Subjects

We previously reported our findings from a randomized, multicenter clinical restenosis trial with cilazapril in patients with coronary artery disease ${ }^{10}$ In brief, of 128 patients (94 males) who underwent successful coronary balloon angioplasty, 69 (48 males; mean age, 64 years) were enrolled if they had undergone an oral glucose tolerance test (OGTT) and their quantitative coronary angiography (QCA) findings were available. Patients were excluded if they had been diagnosed as diabetic and were being treated with insulin.

Informed consent was obtained from all patients participating in this study.

\section{PTCA Procedure and Quantitative Coronary Angiography Analysis}

All patients received a bolus of 10,000 IU heparin intravenously and $5 \mathrm{mg}$ of isosorbide dinitrate intracoronary. Angiography was performed before and immediately after PTCA and at follow-up 6 months after successful PTCA, but was performed earlier if clinically indicated. Off-line QCA was conducted using CARDIO 500 (Kontron Instruments, Inc, Everett, MA, USA) with the view revealing the highest degree of stenosis. All angiographic analyses were performed at a core hospital whose staff did not have access to the clinical findings. Reference diameter (RD), minimal lumen diameter (MLD), and percent diameter stenosis (\%DS) were calculated. Late loss was defined as the difference between MLD after PTCA and follow-up MLD. Restenosis was defined as the presence of $\geq 50 \%$ stenosis at follow-up. Patients were considered to have restenosis when the \%DS of the main culprit lesion was more than $50 \%$ at follow-up if they had undergone multilesion angioplasty. The main culprit lesion was defined as 
Table 1 Clinical Characteristics

\begin{tabular}{lccc}
\hline \hline & $\begin{array}{c}\text { Restenosis } \\
(n=31)\end{array}$ & $\begin{array}{c}\text { No restenosis } \\
(n=38)\end{array}$ & $p$ value \\
\hline Age $($ years) & $64.7 \pm 1.5$ & $63.2 \pm 1.3$ & 0.44 \\
Males $(\%)$ & 77.4 & 63.2 & 0.20 \\
Previous myocardial infarction $(\%)$ & 48.4 & 44.7 & 0.76 \\
Hypertension $(\%)$ & 58.1 & 52.6 & 0.65 \\
Diabetes mellitus $(\%)$ & 12.9 & 31.6 & 0.07 \\
History of smoking $(\%)$ & 45.2 & 39.5 & 0.63 \\
ACE inhibitor administration $(\%)$ & 32.3 & 57.9 & 0.04 \\
Total cholesterol $(\mathrm{mg} / \mathrm{dl})$ & $202.4 \pm 7.4$ & $219.4 \pm 6.8$ & 0.10 \\
Triglycerides $(\mathrm{mg} / \mathrm{dl})^{*}$ & $115.5(106.9-124.8)$ & $133.0(123.9-142.8)$ & 0.18 \\
HDL cholesterol $(\mathrm{mg} / \mathrm{dl})$ & $42.6 \pm 2.0$ & $44.3 \pm 1.8$ & 0.54 \\
LDL cholesterol $(\mathrm{mg} / \mathrm{dl})$ & $137.8 \pm 8.3$ & $149.7 \pm 7.6$ & 0.29 \\
Fasting glucose $(\mathrm{mg} / \mathrm{dl})$ & $93.9 \pm 4.8$ & $100.2 \pm 4.4$ & 0.34 \\
30 min glucose $(\mathrm{mg} / \mathrm{dl})$ & $155.8 \pm 6.4$ & $155.3 \pm 5.8$ & 0.96 \\
60 min glucose $(\mathrm{mg} / \mathrm{dl})$ & $179.7 \pm 9.4$ & $179.8 \pm 8.3$ & 0.99 \\
120 min glucose $(\mathrm{mg} / \mathrm{dl})$ & $146.8 \pm 12.5$ & $159.5 \pm 11.0$ & 0.45 \\
Fasting insulin $(\mu \mathrm{U} / \mathrm{ml})^{*}$ & $7.7(6.8-8.6)$ & $6.8(6.2-7.6)$ & 0.45 \\
30 min insulin $(\mu \mathrm{U} / \mathrm{ml})^{*}$ & $49.1(42.7-56.5)$ & $30.9(27.2-35.1)$ & 0.02 \\
60 min insulin $(\mu \mathrm{U} / \mathrm{ml})^{*}$ & $70.5(61.9-80.3)$ & $48.2(42.8-54.2)$ & 0.04 \\
120 min insulin $(\mu \mathrm{U} / \mathrm{ml})^{*}$ & $58.6(50.2-68.5)$ & $44.9(39.0-51.6)$ & 0.21 \\
$\Sigma$ insulin $(\mu \mathrm{U} / \mathrm{ml}) *$ & $201.2(179.3-225.7)$ & $144.9(130.6-160.8)$ & 0.04 \\
\hline
\end{tabular}

Values are given as means $\pm S E$, (95\% confidence intervals), or percentages. *Values are back-transformed from log transformations.

$\Sigma$ insulin is the sum of fasting, $30 \mathrm{~min}, 60 \mathrm{~min}$, and $120 \mathrm{~min}$ insulin levels.

the lesion that had a larger RD or a higher \%DS before angioplasty. If we could not decide on a culprit lesion with these criteria, we chose the lesion that had a greater difference between the RD and the MLD before angioplasty.

\section{Blood Sampling}

Before PTCA, blood samples were obtained in the morning after a 12-h fast to measure the fasting levels of total cholesterol, high-density lipoprotein (HDL) cholesterol, and triglycerides by enzymatic methods. Low-density lipoprotein (LDL) cholesterol was calculated using Friedewald's formula. Plasma glucose insulin concentrations were measured before, 30,60, and $120 \mathrm{~min}$ after an oral challenge with $75 \mathrm{~g}$ glucose (OGTT). The homeostasis model insulin resistance index (HOMA index) was calculated using the formula: fasting plasma glucose $(\mathrm{mg} / \mathrm{dl}) \times$ fasting plasma insulin $\mu \mathrm{U} / \mathrm{ml}) / 405 .^{11}$ Plasma glucose was measured by the glucokinase method, and insulin was measured by a radioimmunoassay.

\section{Statistic Analysis}

Values are expressed as means \pm SE. Differences between the means of the 2 groups were evaluated with a Student's 2-tailed t-test. Logarithmic transformations of triglycerides and insulin were performed because these variables showed a skewed distribution in all statistical analyses including these variables as continuous variables. They were reconverted to their original form before presentation. Analysis of covariance was used to assess the relationship between the \%DS, MLD at follow-up, late loss and hyperinsulinemia adjusted for age, gender, previous myocardial infarction, administration of angiotensin converting enzyme (ACE) inhibitors, coronary risk factors, RD before PTCA, and MLD immediately after PTCA. Contingency tables of quartiles of insulin concentrations in individuals were compared by chi-square or Fisher's exact test. Logistic regression was used to calculate the relative risk ratio (RR) and $95 \%$ confidence intervals (CI) for the association between restenosis and hyperinsulinemia. Additional analyses were adjusted for age, gender, previous myocardial infarction, and coronary risk factors, including hypertension, dyslipidemia, smoking, and diabetes mellitus (DM). Statistical analyses were carried out using the SAS program (JMP 3.0). A level of $\mathrm{p}<0.05$ was considered statistically significant.

\section{Results}

\section{Patient's Characteristics}

The study population consisted of 69 patients with 76 vessels and 90 lesions. Of the 69 patients with initially successful PTCA, 31 (45\%) developed restenosis (Table 1). There were no significant differences between the 2 groups with regard to age, gender, incidence of hypertension, dyslipidemia, previous myocardial infarction, or history of smoking. The prevalence of DM tended to be higher in patients without restenosis than in those with restenosis. A greater number of patients without restenosis were receiving ACE inhibitors. Serum levels of total cholesterol, triglycerides, HDL cholesterol, and plasma glucose levels before and after glucose load were not different between the 2 groups. However, plasma 30-min and 60-min insulin levels after glucose load and the sum of insulin levels during OGTT ( $\Sigma$ insulin) were significantly higher in patients with restenosis than in those without restenosis $(\mathrm{p}<0.05)$. Plasma fasting and 120-min insulin levels were slightly higher in patients with restenosis, but not significantly.

\section{Hyperinsulinemia and Restenosis}

Restenosis rates and the relative risks for restenosis by quartiles of insulin levels are shown in Table2. The restenosis rate was significantly higher in the highest quartile of 30 min, $60 \mathrm{~min}$, and $\Sigma$ insulin than in the 3 lower quartiles, and tended to be higher in the highest quartile of fasting insulin. When restenosis was evaluated in terms of vessels or lesions, both restenosis per vessel and that per lesion were associated with hyperinsulinemia (Table 3 ).

In a multivariable prediction model that includes age, gender, previous myocardial infarction, administration of 
Table 2 Rates and Relative Risks for Restenosis in Relation to Insulin Concentrations

\begin{tabular}{|c|c|c|c|c|c|}
\hline & \multirow[b]{2}{*}{$\mu U / m l$} & \multirow[b]{2}{*}{$(n)$} & \multicolumn{3}{|c|}{ Restenosis } \\
\hline & & & Rate (\%) & $\begin{array}{l}\text { Relative risk }(95 \% \text { CI), } p \text { value } \\
\text { Quartile } 4 \text { vs Quartiles 1-3 }\end{array}$ & $p$ value for trend \\
\hline \multicolumn{6}{|l|}{ Fasting insulin } \\
\hline Quartile 1 & $<4.7$ & (17) & 41.2 & & \\
\hline Quartile 2 & $4.7-$ & (17) & 52.9 & & \\
\hline Quartile 3 & 7.3- & (18) & 22.2 & & \\
\hline Quartile 4 & $10.9-$ & (17) & 64.7 & $1.71(0.98-3.92), 0.06$ & 0.07 \\
\hline \multicolumn{6}{|l|}{30 min insulin } \\
\hline Quartile 1 & $<21.3$ & (17) & 41.2 & & \\
\hline Quartile 2 & $21.3-$ & (17) & 29.4 & & \\
\hline Quartile 3 & $41.0_{-}$ & (18) & 33.3 & & \\
\hline Quartile 4 & $72.2-$ & (17) & 76.5 & $2.48(1.37-4.94), 0.005$ & 0.02 \\
\hline \multicolumn{6}{|l|}{60 min insulin } \\
\hline Quartile 1 & $<33.6$ & (17) & 44.4 & & \\
\hline Quartile 2 & $33.6-$ & (17) & 29.4 & & \\
\hline Quartile 3 & $63.6-$ & (18) & 37.5 & & \\
\hline Quartile 4 & $102.0_{-}$ & (17) & 66.7 & $1.83(1.06-3.33), 0.04$ & 0.14 \\
\hline \multicolumn{6}{|l|}{120 min insulin } \\
\hline Quartile 1 & $<32.8$ & (17) & 35.3 & & \\
\hline Quartile 2 & $32.8-$ & (17) & 47.1 & & \\
\hline Quartile 3 & $56.2-$ & (18) & 38.9 & & \\
\hline Quartile 4 & $86.7-$ & (17) & 58.8 & $1.45(0.84-2.58), 0.19$ & 0.52 \\
\hline \multicolumn{6}{|l|}{$\Sigma$ insulin } \\
\hline Quartile 1 & $<113.0$ & $(17)$ & 41.2 & & \\
\hline Quartile 2 & $113.0_{-}$ & (17) & 29.4 & & \\
\hline Quartile 3 & 174.4 & (18) & 27.8 & & \\
\hline Quartile 4 & $256.3-$ & (17) & 82.4 & 3.10 (1.65-6.77), 0.001 & 0.004 \\
\hline
\end{tabular}

$\Sigma$ insulin is the sum of fasting, $30 \mathrm{~min}, 60 \mathrm{~min}$, and $120 \mathrm{~min}$ insulin levels. CI, confidence interval.

Table 3 Restenosis Rate at Follow-up Angiography

\begin{tabular}{lcccccc}
\hline \hline & \multicolumn{2}{c}{$Q 1-3 \Sigma$ insulin } & & \multicolumn{2}{c}{$Q 4 \Sigma$ insulin } & \multirow{2}{*}{ p value } \\
\cline { 2 - 3 } & Total & Restenosis $(\%)$ & & Total & Restenosis $(\%)$ & \\
\hline Patients $(n)$ & 52 & $17(32.7)$ & & 17 & $14(82.4)$ & 0.0004 \\
Vessels $(n)$ & 56 & $17(30.4)$ & & 20 & $14(70.0)$ & \\
Lesions $(n)$ & 63 & $18(28.6)$ & & 27 & $14(51.9)$ & \\
\hline
\end{tabular}

$\Sigma$ insulin is the sum of fasting, $30 \mathrm{~min}, 60 \mathrm{~min}$, and $120 \mathrm{~min}$ insulin levels. $Q$, quartile.

Table 4 Quantitative Angiographic Analysis

\begin{tabular}{|c|c|c|c|}
\hline & $\underset{(n=52)}{1-3 \text { Quartile } \sum \text { insulin }}$ & $\begin{array}{c}\text { Highest Quartile } \Sigma \text { insulin } \\
(n=17)\end{array}$ & $p$ value \\
\hline \multicolumn{4}{|l|}{$R D(\mathrm{~mm})$} \\
\hline Before PTCA & $2.72 \pm 0.10$ & $2.70 \pm 0.17$ & 0.91 \\
\hline After PTCA & $2.67 \pm 0.08$ & $2.60 \pm 0.14$ & 0.65 \\
\hline Follow-up & $2.52 \pm 0.09$ & $2.65 \pm 0.16$ & 0.47 \\
\hline \multicolumn{4}{|l|}{$M L D(m m)$} \\
\hline Before PTCA & $0.83 \pm 0.05$ & $0.58 \pm 0.10$ & 0.02 \\
\hline After PTCA & $1.96 \pm 0.06$ & $1.85 \pm 0.10$ & 0.35 \\
\hline Follow-up & $1.47 \pm 0.09$ & $0.95 \pm 0.15$ & 0.005 \\
\hline \multicolumn{4}{|l|}{$\% D S$} \\
\hline Before PTCA & $70.3 \pm 1.6$ & $78.1 \pm 2.9$ & 0.02 \\
\hline After PTCA & $25.3 \pm 1.8$ & $29.0 \pm 2.4$ & 0.32 \\
\hline Follow-up & $40.5 \pm 3.3$ & $66.3 \pm 5.8$ & 0.0003 \\
\hline Late loss $(\mathrm{mm})$ & $0.49 \pm 0.08$ & $0.90 \pm 0.15$ & 0.02 \\
\hline
\end{tabular}

Values are given as means $\pm S E . \Sigma$ insulin is the sum of fasting, $30 \mathrm{~min}, 60 \mathrm{~min}, 120 \mathrm{~min}$ insulin levels. RD, reference diameter; $P T C A$, percutaneous transluminal coronary angioplasty; MLD, minimal lumen diameter; $D S$, diameter stenosis.

ACE inhibitors, and coronary risk factors, including hypertension, dyslipidemia, smoking, DM, the highest quartile of $\Sigma$ insulin was associated with restenosis (risk ratio $=3.43$, 95\% CI 1.51-9.57, p<0.01). Administration of ACE inhibitors prevented restenosis.

\section{HOMA Index and Restenosis}

The HOMA index was not different between the patients with and without restenosis $(2.21 \pm 0.27$ vs $2.04 \pm 0.24)$. The distribution of restenosis rates along quartiles of the HOMA index detected no obvious trend (from first to last quartile, percentage of restenosis: $47.3 \%, 35.3 \%, 31.3 \%, 58.8 \%$ ). 
Table 5 Quantitative Angiographic Analysis

\begin{tabular}{lccc}
\hline \hline & \multicolumn{2}{c}{$\sum$ insulin } & \\
\cline { 2 - 3 } & Quartiles 1-3 & Quartile 4 \\
\hline Nondiabetic patients & $(n=37)$ & $(n=16)$ & \\
MLD at follow-up $(\mathrm{mm})$ & $1.43 \pm 0.10$ & $0.90 \pm 0.15$ & 0.006 \\
\%DS at follow-up & $42.5 \pm 4.0$ & $67.7 \pm 6.1$ & 0.001 \\
Late loss $(\mathrm{mm})$ & $0.63 \pm 0.10$ & $0.92 \pm 0.15$ & 0.10 \\
Restenosis $(\%)$ & 35.1 & 87.5 & 0.002 \\
Single lesion angioplasty & $(n=39)$ & $(n=9)$ & \\
MLD at follow-up $(\mathrm{mm})$ & $1.46 \pm 0.11$ & $0.84 \pm 0.23$ & 0.02 \\
\%DS at follow-up & $40.8 \pm 4.1$ & $69.8 \pm 8.5$ & 0.004 \\
Late loss $($ mm) & $0.47 \pm 0.10$ & $0.97 \pm 0.22$ & 0.04 \\
Restenosis $(\%)$ & 30.8 & 77.8 & 0.009 \\
\hline
\end{tabular}

Values are given as means $\pm S E$ or percentages. $\Sigma$ insulin is the sum of fasting, $30 \mathrm{~min}, 60 \mathrm{~min}, 120 \mathrm{~min}$ insulin levels. RD, reference diameter; MLD, minimal lumen diameter; DS, diameter stenosis.

The risk ratio for restenosis comparing patients in the highest HOMA index with those in the combined 3 lower quartiles was $1.53(95 \% \mathrm{CI}, 0.88-2.73)$. In nondiabetic patients, the risk ratio was 4.08 (95\% CI, 1.67-17.93).

\section{Quantitative Coronary Angiography Analysis}

Quantitative angiographic findings along quartiles of $\Sigma$ insulin levels are shown in Table 4. There were no significant differences in RD, MLD after PTCA, and \%DS after PTCA between the 2 groups. MLD before PTCA was smaller and \%DS before PTCA was higher in the highest $\Sigma$ insulin quartile than in the combined 3 lower quartiles. MLD at follow-up was smaller, and \%DS at follow-up was higher and late loss was greater in the highest $\Sigma$ insulin quartile. The \%DS at follow-up was higher in the highest $\Sigma$ insulin quartile than in the combined 3 lower quartiles after adjustment for \%DS before angioplasty $(65.8 \pm 6.6 \mathrm{vs}$ $40.7 \pm 3.4 \%, \mathrm{p}=0.006$ ) and after adjustment for MLD before angioplasty $(64.8 \pm 6.3$ vs $41.4 \pm 3.5 \%, \mathrm{p}=0.002)$.

After adjustment for age, gender, previous myocardial infarction, administration of ACE inhibitors, coronary risk factors, RD before PTCA, and MLD after PTCA, \%DS at follow-up was 57.2 \pm 7.6 in the highest $\Sigma$ insulin quartile and $37.7 \pm 3.8$ in the other group $(\mathrm{p}=0.01)$, MLD at followup tended to be smaller, and late loss tended to be greater in the highest $\Sigma$ insulin quartile $(1.24 \pm 0.18$ vs $1.55 \pm 0.09 \mathrm{~mm}$, $\mathrm{p}=0.09 ; 0.69 \pm 0.18$ vs $0.37 \pm 0.09 \mathrm{~mm}, \mathrm{p}=0.08)$.

\section{Hyperinsulinemia and Restenosis in Nondiabetic \\ Patients or Who Underwent the Single-Lesion \\ PTCA Procedure (Table 5)}

In a subgroup of nondiabetic patients $(n=53)$, MLD at follow-up was smaller, \%DS was higher, and late loss tended to be greater in patients with the highest $\Sigma$ insulin quartile than in the other group. The highest $\Sigma$ insulin quartile showed a higher restenosis rate $(87.5 \%)$ and was associated with restenosis (risk ratio $=3.59 ; 95 \%$ CI, 1.74-9.53, $\mathrm{p}=0.002$ ). Further adjustments for age, gender, previous myocardial infarction, administration of ACE inhibitors, and coronary risk factors, gave a risk ratio of 4.95 (95\% CI, 1.72-21.3, $\mathrm{p}=0.01$ ).

After adjustment for age, gender, previous myocardial infarction, administration of ACE inhibitors, coronary risk factor, RD before PTCA, and MLD after PTCA, MLD at follow-up tended to be smaller, \%DS at follow-up tended to be higher, and late loss tended to be greater in the highest $\Sigma$ insulin quartile $(1.02 \pm 0.19$ vs $1.41 \pm 0.10, \mathrm{p}=0.08 ; 60.2 \pm$ 8.1 vs $43.4 \pm 4.5, \mathrm{p}=0.09 ; 0.96 \pm 0.19$ vs $0.58 \pm 0.10, \mathrm{p}=0.08)$.
In a subgroup of patients $(n=48)$ who underwent the single-lesion PTCA procedure, MLD at follow-up was smaller, \%DS was higher, and late loss tended to be greater in patients with the highest $\Sigma$ insulin quartile than in the other group. The highest $\Sigma$ insulin quartile had a higher restenosis rate $(77.8 \%)$ and was associated with restenosis (risk ratio $=2.81 ; 95 \% \mathrm{CI}, 1.28-7.64, \mathrm{p}=0.02$ ). Further adjustments for age, gender, previous myocardial infarction, administration of ACE inhibitors, and coronary risk factors, gave a risk ratio of 3.96 (95\% CI, 1.48-24.3, p=0.02).

After adjustment for age, gender, previous myocardial infarction, administration of ACE inhibitors, coronary risk factor, RD before PTCA, and MLD after PTCA, MLD at follow-up was smaller, \%DS at follow-up was larger, and late loss was greater in the highest $\Sigma$ insulin quartile $(0.82 \pm 0.23$ vs $1.45 \pm 0.11 \mathrm{~mm}, \mathrm{p}=0.01 ; 78.9 \pm 9.2$ vs $42.2 \pm 4.3$, $\mathrm{p}=0.0003 ; 1.10 \pm 0.23$ vs $0.46 \pm 0.11 \mathrm{~mm}, \mathrm{p}=0.008)$.

\section{Discussion}

The findings of the present study demonstrated that hyperinsulinemia is a strong independent risk factor of restenosis after angioplasty, as reported by a few other studies?,8 One study has reported a negative association between hyperinsulinemia and restenosis after PTCA in patients with DM? The present study population included patients with DM, but even after excluding them, a positive association between hyperinsulinemia and restenosis remained (Table 5). The HOMA index as a measure of insulin resistance was also associated with restenosis in nondiabetic patients.

\section{Diabetes Mellitus and Restenosis}

Several studies have demonstrated that diabetes is a strong predictor of restenosis after successful balloon angioplasty ${ }^{12,13}$ or stent implantation, ${ }^{14-16}$ but others ${ }^{17,18}$ have not. Recently, Asakura et al demonstrated that restenosis was significantly more frequent in poorly controlled diabetic patients compared with moderately or well-controlled diabetic patients or nondiabetic subjects! ${ }^{13}$ Most patients with DM in the present study population were moderately or well controlled, which might explain the reason for the lack of an effect on restenosis. Potential factors promoting restenosis in diabetic patients are elevated glucose or insulin levels. ${ }^{19}$

\section{Hyperinsulinemia and Restenosis}

The mechanisms of restenosis are not fully understood, 
but some causal factors have been reported: platelet aggregation,20 elastic recoil21 thrombus formation,2 SMC proliferation and migration, ${ }^{23}$ extracellular matrix production, 22,24 spasm, 25 and vascular remodeling. 26 Most of these mechanisms are associated with insulin action in part.

Hyperinsulinemia is associated with increased plasminogen activator inhibitor 1 activity ${ }^{27}$ and its gene expression, 28 thereby attenuating fibrinolysis, which may contribute to acceleration of thrombus formation. Proliferation and migration of SMCs is promoted by increased insulin levels; insulin-like growth factor 1 (IGF-1) is a potent mitogen and induces directed migration of arterial SMCs. ${ }^{29}$ Although insulin itself is not a potent mitogen 29 it can stimulate the expression of IGF-130 and is associated with increased extracellular matrix proteins. 4 Vasospasm of the dilated coronary segment is frequently accompanied by resteno$\operatorname{sis}^{25}$ and loss of the endothelium-derived relaxing factor, nitric oxide caused by endothelial denudation, promotes vasospasm, platelet aggregation, and SMC proliferation 31,32 Hypersecretion of insulin may therefore contribute to the pathogenesis of severe coronary vasospasm and increase susceptibility to restenosis ${ }^{33-35}$ although the relation of vasospastic angina to restenosis is still unclear.

Endothelin-1 (ET-1) is a potent vasoconstrictor and mitogenic peptide produced by the vascular endothelium, and insulin stimulates ET-1 secretion ${ }^{36}$ and its gene expression37 Vascular remodeling, the main mechanism of restenosis, is an active process of structural alteration that involves changes in at least 4 cellular processes: cell growth, cell death, cell migration, and production or degradation of extracellular matrix. ${ }^{26}$ Several growth factors, including platelet-derived growth factors, transforming growth factors, and IGF-1, regulate the growth of vascular cells involved in remodeling. ${ }^{26}$ However, it is unclear whether hyperinsulinemia is associated with it.

\section{Hyperinsulinemia, Dyslipidemia, Coronary \\ Atherosclerosis, and Restenosis}

Insulin resistance and compensatory hyperinsulinemia enhance hepatic very-low-density lipoprotein-triglyceride secretion, 38 which results in increased serum triglycerides and decreased HDL cholesterol concentrations. Furthermore, Haffner et al $^{39}$ suggest that hyperinsulinemia is predictive of an increase in triglycerides and a decrease in HDL cholesterol concentrations. Two additional lipid abnormalities described in hyperinsulinemic individuals are small dense LDL particles and accentuation of postprandial large triglyceride-rich particles, ${ }^{40,41}$ and these lipid abnormalities may contribute to the development of coronary atherosclerosis and restenosis. In the present study, the levels of HDL cholesterol tended to be lower, and the levels of triglycerides slightly higher, and the levels of total cholesterol and LDL cholesterol were slightly lower in the hyperinsulinemic group, but not significantly.

Some studies ${ }^{42,43}$ have suggested that hyperlipidemia may be associated with increased restenosis, but a large clinical trial ${ }^{44}$ indicated that there was no association between hyperlipidemia and restenosis. Levels of total cholesterol, triglycerides, HDL cholesterol, and LDL cholesterol were not associated with restenosis in the present study.

\section{Study Limitations}

Although this trial was a multicenter, prospective, randomized study, the major limitations of the present study were that it was not specifically designed to address the relationship between restenosis after angioplasty and hyperinsulinemia and our study group was small. To compensate for these limitations, we conducted the serial QCA measurements in a blinded manner at a core hospital.

\section{Conclusions}

Plasma insulin levels were higher in patients with restenosis than in patients without restenosis. MLD at follow-up was smaller, and \%DS at follow-up was higher and late loss was greater in patients with hyperinsulinemia. Even after adjustment for coronary risk factors and administration of ACE inhibitors, an association of hyperinsulinemia to restenosis remained. These findings indicate that hyperinsulinemia is a strong independent risk factor for restenosis.

\section{References}

1. Liu MW, Roubin GS, King SB III: Restenosis after coronary angioplasty. Potential biologic determinants and role of intimal hyperplasia. Circulation 1989; 79: 1374-1387

2. Stout RW, Bierman EL, Ross R: Effect of insulin on the proliferation of cultured primate arterial smooth muscle cells. Circ Res 1975; 36: 319-327

3. Pfeifle B, Ditschuneit H: Effect of insulin on growth of cultured human arterial smooth muscle cells. Diabetologia 1981; 20: 155-158

4. Hill DJ, Logan A, McGarry M, De Sousa D: Control of protein and matrix-molecule synthesis in isolated ovine fetal growth-plate chondrocytes by the interactions of basic fibroblast growth factor, insulinlike growth factors-I and -II, insulin and transforming growth factorbeta 1. J Endocrinol 1992; 133: 363-373

5. Ridray S, Heudes D, Michel O, Penicaud L, Ktorza A: Increased SMC proliferation after endothelial injury in hyperinsulinemic obese Zucker rats. Am J Physiol 1994; 267: H1976-H1983

6. Law RE, Meehan WP, Xi XP, Graf K, Wuthrich DA, Coats W, et al: Troglitazone inhibits vascular smooth muscle cell growth and intimal hyperplasia. J Clin Invest 1996; 98: 1897-1905

7. Nishimoto Y, Miyazaki Y, Toki Y, Murakami R, Shinoda M, Fukushima A, et al: Enhanced secretion of insulin plays a role in the development of atherosclerosis and restenosis of coronary arteries: Elective percutaneous transluminal coronary angioplasty in patients with effort angina. J Am Coll Cardiol 1998; 32: 1624-1629

8. Osanai H, Kanayama H, Miyazaki Y, Fukushima A, Shinoda M, Ito T: Usefulness of enhanced insulin secretion during an oral glucose tolerance test as a predictor of restenosis after direct percutaneous transluminal coronary angioplasty during acute myocardial infarction in patients without diabetes mellitus. Am J Cardiol 1998; 81: 698-701

9. Rabbani LE, Edelman ER, Ganz P, Selwyn AP, Loscalzo J, Bittl JA: Relation of restenosis after excimer laser angioplasty to fasting insulin levels. Am J Cardiol 1994; 73: 323-327

10. Yamabe T, Imazu M, Yamamoto H, Ueda H, Hattori Y, Hayashi Y, et al: Effect of cilazapril on vascular restenosis after percutaneous transluminal coronary angioplasty. Coron Artery Dis 1995; 6: $573-$ 579

11. Matthews DR, Hosker JP, Rudenski AS, Naylor BA, Treacher DF, Turner RC: Homeostasis model assessment: Insulin resistance and beta-cell function from fasting plasma glucose and insulin concentrations in man. Diabetologia 1985; 28: 412-419

12. Bach R, Jung F, Kohsiek I, Ozbek C, Spitzer S, Scheller B, et al: Factors affecting the restenosis rate after percutaneous transluminal coronary angioplasty. Thromb Res 1994; 74(Suppl 1): S55-S67

13. Asakura Y, Suzuki M, Nonogi H, Haze K, Sato A, Inada H, et al: Restenosis after percutaneous transluminal coronary angioplasty in patients with non-insulin-dependent diabetes mellitus (NIDDM). $J$ Cardiovasc Risk 1998; 5: $331-334$

14. Carrozza JP, Kuntz RE, Fishman RF, Baim DS: Restenosis after arterial injury caused by coronary stenting in patients with diabetes mellitus. Ann Intern Med 1993; 118: 344-349

15. Kornowski R, Mintz GS, Kent KM, Pichard AD, Satler LF, Bucher TA, et al: Increased restenosis in diabetes mellitus after coronary interventions is due to exaggerated intimal hyperplasia: A serial intravascular ultrasound study. Circulation 1997; 95: 1366-1369

16. Elezi S, Kastrati A, Pache J, Wehinger A, Hadamitzky M, Dirschinger 
$\mathrm{J}$, et al: Diabetes mellitus and the clinical and angiographic outcome after coronary stent placement. J Am Coll Cardiol 1998; 32: $1866-$ 1873

17. Fleck E, Regitz V, Lehnert A, Dacian S, Dirschinger J, Rudolph W: Restenosis after balloon dilatation of coronary stenosis, multivariate analysis of potential risk factors. Eur Heart J 1988; 9(SupplC): 1518

18. Gurlek A, Dagalp Z, Oral D, Omurlu K, Erol C, Akyol T, et al: Restenosis after transluminal coronary angioplasty: A risk factor analysis. J Cardiovasc Risk 1995; 2: 51-55

19. Aronson D: Restenosis in diabetic patients: Is hyperinsulinemia the culprit? Circulation 1996; 94: 3003-3005

20. Wilcox JN: Molecular biology: Insight into the causes and prevention of restenosis after arterial intervention. Am J Cardiol 1993; 72: $88 \mathrm{E}-95 \mathrm{E}$

21. Ip JH, Fuster V, Israel D, Badimon L, Badimon J, Chesebro JH: The role of platelets, thrombin and hyperplasia in restenosis after coronary angioplasty. J Am Coll Cardiol 1991; 17: 77B - 88B

22. Schwartz RS, Holmes DR, Topol EJ: The restenosis paradigm revisited: An alternative proposal for cellular mechanisms. J Am Coll Cardiol 1992; 20: $1284-1293$

23. Epstein SE, Speir E, Unger EF, Guzman RJ, Finkel T: The basis of molecular strategies for treating coronary restenosis after angioplasty. J Am Coll Cardiol 1994; 23: 1278-1288

24. Baykal D, Schmedtje JF, Runge MS: Role of the thrombin receptor in restenosis and atherosclerosis. Am J Cardiol 1995; 75: 82B-87B

25. Bertrand ME, Lablanche JM, Fourrier JL, Gommeaux A, Ruel M: Relation to restenosis after percutaneous transluminal coronary angioplasty to vasomotion of the dilated coronary arterial segment. Am J Cardiol 1989; 63: 277-281

26. Gibbons GH, Dzau VJ: The emerging concept of vascular remodeling. N Engl J Med 1994; 330: 1431-1438

27. McGill JB, Schneider DJ, Arfken CL, Lucore CL, Sobel BE: Factors responsible for impaired fibrinolysis in obese subjects and NIDDM patients. Diabetes 1994; 43: 104-109

28. Nordt TK, Sawa H, Fujii S, Sobel BE: Induction of plasminogen activator inhibitor type-1 (PAI-1) by proinsulin and insulin in vivo. Circulation 1995; 91: 764-770

29. Bornfeldt KE, Raines EW, Nakano T, Graves LM, Krebs EG, Ross $\mathrm{R}$ : Insulin-like growth factor-I and platelet-derived growth factor-BB induce directed migration of human arterial smooth muscle cells via signaling pathways that are distinct from those of proliferation. $J$ Clin Invest 1994; 93: 1266-1274

30. Murphy LJ, Ghahary A, Chakrabarti S: Insulin regulation of IGF-I expression in rat aorta. Diabetes 1990; 39: 657-662

31. Fuster V, Badimon L, Badimon JJ, Chesebro JH: The pathogenesis of coronary artery disease and the acute coronary syndromes (2). $N$
Engl J Med 1992; 326: 310-318

32. Ware JA, Heistad DD: Seminars in medicine of the Beth Israel Hospital, Boston. Platelet-endothelium interactions. $N$ Engl J Med 1993; 328: 628-635

33. Botker HE, Skjaerbaek C, Eriksen UH, Schmitz O, Orskov H: Insulin-like growth factor-I, insulin, and angina pectoris secondary to coronary atherosclerosis, vasospasm, and syndrome X. Am J Cardiol 1997; 79: $961-963$

34. Suzuki M, Nishizaki M, Arita M, Kakuta T, Numano F: Impaired glucose tolerance with late hypersecretion of insulin during oral glucose tolerance test in patients with vasospastic angina. $J$ Am Coll Cardiol 1996; 27: 1458-1463

35. Watanabe I, Kawamura I, Satoh K, Nagao K, Kushiro T, Kanmatsuse K: Effect of insulin resistance on the endothelial vasomotor function of the coronary artery of nondiabetic patients. Jpn Circ J 1999; 63: 589-592

36. Ferri C, Pittoni V, Piccoli A, Laurenti O, Cassone MR, Bellini C, et al: Insulin stimulates endothelin-1 secretion from human endothelial cells and modulates its circulating levels in vivo. J Clin Endocrinol Metab 1995; 80: 829-835

37. Oliver FJ, de la Rubia G, Feener EP, Lee ME, Loeken MR, Shiba T, et al: Stimulation of endothelin-1 gene expression by insulin in endothelial cells. J Biol Chem 1991; 266: 23251-23256

38. Reaven GM: Insulin resistance, hyperinsulinemia, and hypertriglyceridemia in the etiology and clinical course of hypertension. Am J Med 1991; 90: 7S-12S

39. Haffner SM, Valdez RA, Hazuda HP, Mitchell BD, Morales PA, Stern MP: Prospective analysis of the insulin-resistance syndrome (syndrome X). Diabetes 1992; 41: 715-722

40. Reaven GM, Chen YD, Jeppesen J, Maheux P, Krauss RM: Insulin resistance and hyperinsulinemia in individuals with small, dense low density lipoprotein particles. J Clin Invest 1993; 92: 141-146

41. Kobayashi H, Nakamura T, Miyaoka K, Nishida M, Funahashi T, Yamashita S, et al: Visceral fat accumulation contributes to insulin resistance, small-sized low-density lipoprotein, and progression of coronary artery disease in middle-aged non-obese Japanese men. Jpn Circ J 2001; 65: 193-199

42. Reis GJ, Kuntz RE, Silverman DI, Pasternak RC: Effects of serum lipid levels on restenosis after coronary angioplasty. Am J Cardiol 1991; 68: $1431-1435$

43. Shah PK, Amin J: Low high density lipoprotein level is associated with increased restenosis rate after coronary angioplasty. Circulation 1992; 85: 1279-1285

44. Violaris AG, Melkert R, Serruys PW: Influence of serum cholesterol and cholesterol subfractions on restenosis after successful coronary angioplasty: A quantitative angiographic analysis of 3336 lesions. Circulation 1994; 90: 2267-2279 